\title{
CrystEngComm
}
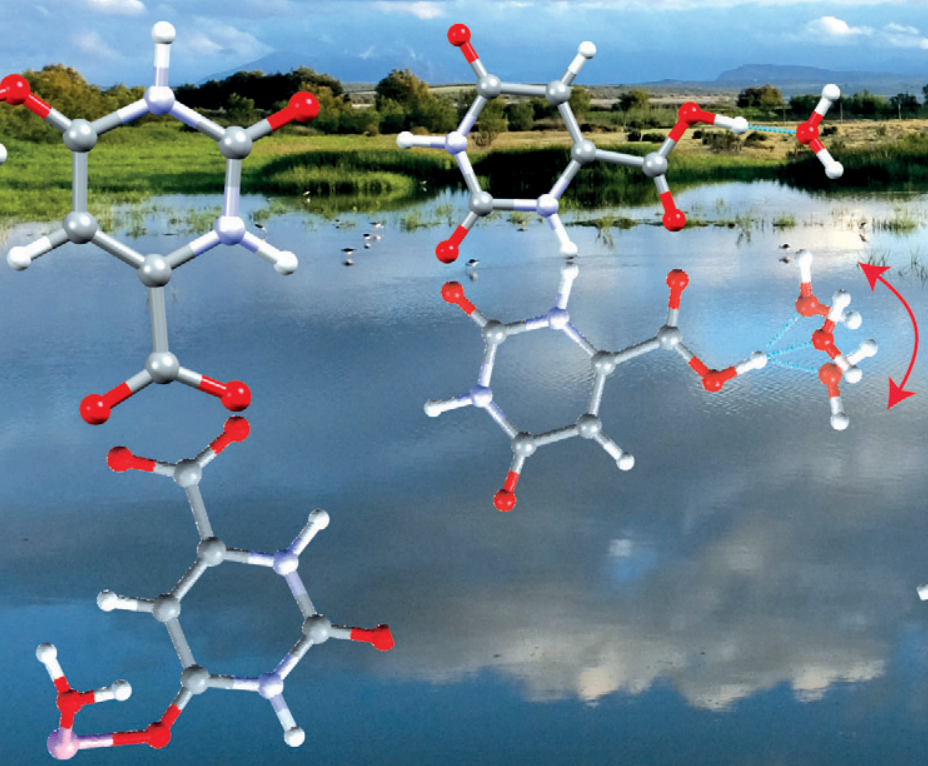

$$
\text { comm }
$$




\title{
CrystEngComm
}

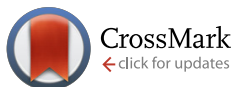

Cite this: CrystEngComm, 2017, 19, 224

Received 29th September 2016, Accepted 2nd November 2016

DOI: $10.1039 / c 6 c e 02101 \mathrm{~h}$

www.rsc.org/crystengcomm

\section{A combined NMR crystallographic and PXRD investigation of the structure-directing role of water molecules in orotic acid and its lithium and magnesium salts $\uparrow$}

\author{
Ann-Christin Pöppler, \$ David Walker and Steven P. Brown
}

\begin{abstract}
Despite the abundance of hydrates, their multifaceted nature and hydration/dehydration behaviour is still not fully understood. For the example of orotic acid monohydrate and its lithium and magnesium hydrate salts, we show how NMR crystallography, namely a combination of solid-state NMR with a focus here on ${ }^{1} \mathrm{H}$ magic angle spinning (MAS) NMR experiments and first-principles DFT GIPAW (gauge-including projector augmented wave) calculations, can play a valuable role in the characterization of hydrate systems. Starting from lithium orotate monohydrate, a rigid system with a limited number of tightly bound water molecules, the general feasibility of this approach was demonstrated. Moving onto more complex hydrate structures, mobility in the orotic acid monohydrate was observed, while for the most complex hydrate, magnesium orotate octahydrate, a loss of associated water molecules was observed after an overnight MAS NMR experiment. A combined study by experimental MAS NMR, powder X-ray diffraction (PXRD) and thermogravimetric analysis (TGA) revealed changes after vacuum drying as well as after storage of a vacuum dried sample under ambient conditions. Specifically, TGA showed the vacuum dried sample to correspond to a dihydrate, for which no structure has yet been determined by single-crystal X-ray diffraction. An NMR crystallography analysis showed that a combination of putative symmetric and asymmetric dihydrate structures explains the observed changes in the experimental MAS NMR spectra.
\end{abstract}

\section{Introduction}

Hydrates are a very versatile but equally complex group of compounds. At various stages of manufacturing, processing or storing of chemical compounds, the abundance of water facilitates the occurrence of these molecular adducts. Upon uptake of one or several water molecules into an existing ordered structure, the intermolecular interactions and thus a whole range of physicochemical properties, e.g., the packing, density, solubility, bioavailability, stability and mechanical behaviour can change. ${ }^{1,2}$ Considering the fact that approximately one third of all active pharmaceutical ingredients (APIs) can form hydrate structures, ${ }^{3}$ some drug molecules are directly marketed as hydrates and they have also been termed the "nemesis of crystal engineering". " Gaining additional and complementary insights into this class of compounds would

Department of Physics, University of Warwick, Coventry CV4 7AL, UK.

E-mail: S.P.Brown@warwick.ac.uk,A-C.Poppler@warwick.ac.uk

$\dagger$ Electronic supplementary information (ESI) available: For additional information on synthesis and further characterization. See DOI: $10.1039 / \mathrm{c} 6 \mathrm{ce} 02101 \mathrm{~h}$

\$ A.-C. Pöppler is now located at the University of Würzburg, Department of Organic Chemistry, 97074 Wurzburg, Germany. Email: ann-christin.poeppler@uniwuerzburg.de be very valuable for both theoretical understanding as well as for practical applications.

The multitude of existing hydrate structures can be systematically divided into subgroups of stoichiometric and non-stoichiometric hydrates, which can all be further categorized into three classes based on their connectivity: class 1 , isolated hydrates; class 2, channel hydrates (expanded or planar); and class 3, (metal) ion assisted hydrates. ${ }^{5-7}$ While common class 2 representatives usually have lower dehydration temperatures compared to class 1 structures, the strong interactions in ion-associated hydrates are responsible for the considerably higher dehydration temperatures observed in class 3 .

In the field of structure elucidation, NMR crystallography, the combination of experimental solid-state NMR and first principles DFT calculations, is highly complementary to existing diffraction approaches and can be successfully applied to a wide range of different chemical compounds and materials..$^{8-11}$ Due to its particular sensitivity towards the local environment of nuclei, especially hydrogen, solid-state NMR is a powerful indicator of conformational changes, (subtle) variations in molecular packing and underlying interactions as well as of solid-state dynamics. ${ }^{12,13}$ Additionally, as 
solid-state NMR provides a way of studying crystalline forms as well as powdered samples, dosage forms and even amorphous materials, ${ }^{14}$ it is widely used in the field of pharmaceutical research, e.g., for the identification of structures, polymorphs and solvates, ${ }^{5,15-22}$ to study the interactions between the API and excipients ${ }^{23}$ and for the investigation of drug stability.

In the present study, orotic acid monohydrate as well as the corresponding lithium and magnesium orotate hydrates (Scheme 1) are analysed by a combination of solid-state NMR together with GIPAW (CASTEP) ${ }^{24-26}$ calculations, powder X-ray diffraction (PXRD) and thermogravimetric analysis (TGA). These compounds have been tested for very diverse applications such as the treatment of cardiovascular illnesses $^{27-30}$ or bipolar disorder, ${ }^{31,32}$ diagnosis of malfunctions in the pyrimidine metabolism ${ }^{33,34}$ and use as a nucleating agent for the crystallization of biodegradable polymers. ${ }^{35,36}$ Furthermore, they represent a set of structures with, in principle, known single crystal X-ray structures (see Fig. 1), in which each individual compound belongs to a different class of hydrates. Importantly, this NMR crystallography study reveals complexities in structure and dynamics that go beyond the static view of the available crystal structures.

\section{Results and discussion}

\section{Synthetic procedure and structure description}

The hydrate structures for the three compounds - orotic acid, lithium and magnesium orotate - investigated in this work were determined by single-crystal X-ray diffraction more than two decades ago. After verifying the phase purity of the purchased orotic acid monohydrate, the two salts were prepared according to a slightly modified protocol based on the work of Schmidbaur and co-workers. ${ }^{37}$ Both the starting material and the reaction products were subjected to PXRD, IR and TGA measurements to confirm product formation and (phase) purity (see section S2 in the ESI $\dagger$ ). In the following, the three structures are presented with some specific structural features being commented on. Any distances discussed are taken from DFT geometry optimized (CASTEP) data, with the geometry optimisation (i.e., starting with the X-ray diffraction structures and allowing atom positions to move until an energy minimum is reached) being

$$
\begin{aligned}
& \text { orotic acid } \\
& \begin{array}{l}
\text { Orotic acid } \\
\text { monohydrate (1) }
\end{array}
\end{aligned}
$$
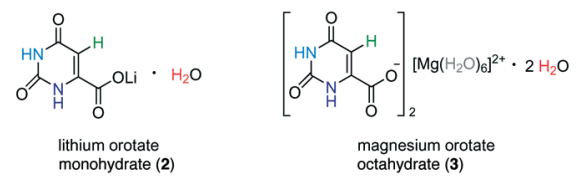

Scheme 1 Molecular formulae of the three structures, orotic acid (1) and its lithium (2) and magnesium (3) salts, which all form different hydrate structures. Lithium orotate forms a contact ion pair (CIP), while in 3, the magnesium atom is separated from the counter ion by a shell of water molecules (solvent separated ion pair - SSIP). Hydrogen atoms are colour coded to facilitate further analysis and discussion below. the first step in an NMR crystallography calculation of NMR chemical shieldings.

The crystallographic data for orotic acid monohydrate (Fig. 1a) was first published in 1973 (CSD code OROTAC) ${ }^{38}$ and later re-determined in 2008 (CSD code OROTAC01). ${ }^{39}$ Both X-ray diffraction analyses were carried out at room temperature yet with different radiation sources $\left(\mathrm{Cu} \mathrm{K} \mathrm{K}_{\alpha}\right.$ and Mo $\mathrm{K}_{\alpha}$ ) and resulted in the same space group $P \overline{1}$ with two equivalent molecules in the crystallographic unit cell being determined concordantly. Strong $\mathrm{N}-\mathrm{H} \cdots \mathrm{O}$ and $\mathrm{O}-\mathrm{H} \cdots \mathrm{O}$ hydrogen bonds to adjacent orotic acid and water molecules are responsible for the formation of planar layers with an interlayer distance of $3.04 \AA$. The water molecules are located in isolated sites forming hydrogen bonds to the host molecule only, and thus this is a class 1 hydrate.

Lithium orotate monohydrate (Fig. 1b) (CSD codes SIMZOD and SIMZOD01), the lithium salt of orotic acid, was initially characterized by $\mathrm{X}$-ray diffraction at room temperature in 1990 and subsequently re-determined at low temperature $(110 \mathrm{~K})$ in $2001 .^{37,40}$ Both data collections were refined in the space group $P \overline{1}$. The lithium ions are directly coordinated to the carboxylate group in a contact ion pair arrangement. Furthermore, they are in their preferred tetrahedral coordination environment being linked to four oxygen sites each. Overall, the formation of staggered layers (ABCBABCB...) with inter-layer distances of (AB) 3.05, (BC) 3.16, (CB) 3.38 and (BA) $3.16 \AA$ is observed. Both the water molecules and the lithium ions act as intra- and inter-layer linker units (see ESI, $†$ Fig. S5). This hydrate is a classical representative of class 3 , a (metal) ion assisted hydrate with strong metal-water interactions, which is underlined by the higher temperature at which loss of water is observed $\left(216^{\circ} \mathrm{C}\right.$ compared to $139^{\circ} \mathrm{C}$ for the acid).

There is a diagonal relationship in the periodic table between lithium and magnesium, i.e., similar ionic radii (73 and $71 \mathrm{pm}$ for four-coordinate, 90 and $86 \mathrm{pm}$ for six-coordinate, 106 and $103 \mathrm{pm}$ for octa-coordinated ions). ${ }^{41,42}$ However, the magnesium salt crystallizes in a very different packing arrangement with the adoption of the monoclinic space group $P 2_{1} / c$ (CSD code SIMZUJ). ${ }^{37}$ The magnesium ion is solvent-separated from the orotate anion by the water molecules forming well known hexaquo complexes. Additional water molecules connect these $\left[\mathrm{Mg}\left(\mathrm{H}_{2} \mathrm{O}\right)_{6}\right]^{2+}$ octahedra with the orotate moieties and they are located in channels along the crystallographic $c$ axis (see ESI, $\uparrow$ Fig. S6). In total, there are eight water molecules per $\mathrm{Mg}^{2+}$ ion. This compound is thus very interesting to study as it contains six water molecules that correspond to a class 3 hydrate, being directly connected to the magnesium ion, and two water molecules in channel environments, i.e., class 2. Analogous to the previously discussed structures, the different fragments in this complex also arrange in parallel layers (ABAB) with alternating distances of (AB) $3.20 \AA$ and (BA) $3.17 \AA$ between each layer. Although neighbouring orotate molecules (adjacent unit cell) are also equally arranged, the planes are slightly offset by $0.38 \AA$ (see Fig. S6 in the ESI†). 
a)

orotic acid monohydrate (1)
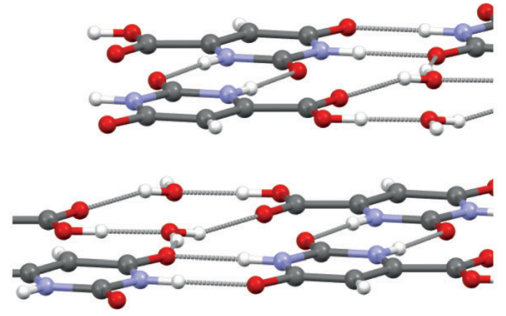

b)

lithium orotate monohydrate (2)

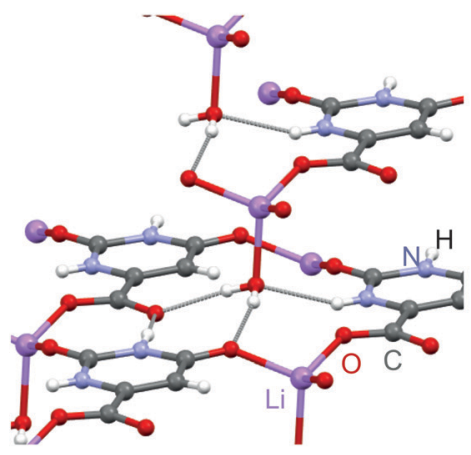

c)

magnesium orotate octahydrate (3)

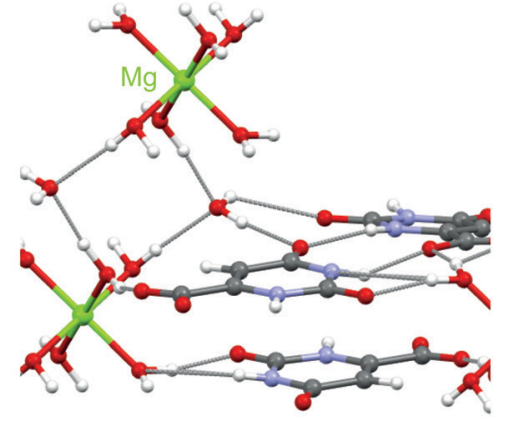

Fig. 1 Overview of the crystal structures for the hydrate samples investigated here: (a) orotic acid monohydrate and its (b) lithium and (c) magnesium salt. All three structures form specific layers, but belong to different classes of hydrate structures. While the lithium salt is a contact ion pair, the magnesium ions are separated from the anionic orotate fragments by solvent (water) molecules.

NMR crystallography of lithium orotate monohydrate (2) the straightforward case

The procedure followed herein is divided into an experimental solid-state NMR part and a theoretical part consisting of DFT GIPAW calculations performed with the program package CASTEP. The experimental and calculated data are then used in conjunction with each other to compare, assign and understand the respective structure in detail. In a first step, the class 3 hydrate lithium orotate 2 was subjected to an NMR crystallographic analysis in order to characterize and describe important interactions and structure determining factors. Due to the tight incorporation of the water molecule into the structure (see TGA data in Fig. S3 of the ESI $\dagger$ ), 2 was expected to be a very stable complex that would serve as an exemplary case for the combined experimental and calculation approach used here.

Fig. 2 presents a comparison of experimental and GIPAW calculated ${ }^{1} \mathrm{H}$ one pulse and ${ }^{1} \mathrm{H}$ double-quantum (DQ)- ${ }^{1} \mathrm{H}$ single-quantum (SQ) NMR data. For the ${ }^{1} \mathrm{H}$ NMR spectrum at $56 \mathrm{kHz}$ magic angle spinning (MAS) (Fig. 2a), colour-coded bars corresponding to the different chemical moieties indicate GIPAW calculated ${ }^{1} \mathrm{H}$ chemical shifts. These were obtained by a geometry optimization of the crystal structure with the program package CASTEP followed by chemical shielding calculations based on the geometry optimized structure employing the GIPAW method. ${ }^{24,26}$ While only two resonances are resolved in the one-dimensional ${ }^{1} \mathrm{H}$ MAS spectrum in Fig. 2a, good agreement between experiment and GIPAW calculation is observed. For ${ }^{1} \mathrm{H}$ chemical shifts, agreement between the experiment and the GIPAW calculation is usually within $0.3 \mathrm{ppm},{ }^{43,44}$ though there can be greater discrepancy of hydrogen-bonded sites due to the temperature dependence of the experimental chemical shifts. ${ }^{45,46}$

The ${ }^{1} \mathrm{H}$ DQ $\mathrm{MAS}^{47}$ spectrum of 2 in Fig. $2 \mathrm{~b}$ was recorded using one rotor period of BABA recoupling at $56 \mathrm{kHz}$ MAS. $^{48,49}$ In such a spectrum, the observation of doublequantum correlation peaks indicates close proximity (typically below $\sim 3.5 \AA$ ) between two protons with the peak(s) in the double-quantum dimension appearing at a value corresponding to the sum of the single-quantum chemical shifts of the two protons. ${ }^{12,47}$ For example, consider the almost ondiagonal DQ peak at $\delta_{\mathrm{DQ}} \sim 11.1+10.8=21.9 \mathrm{ppm}$; this

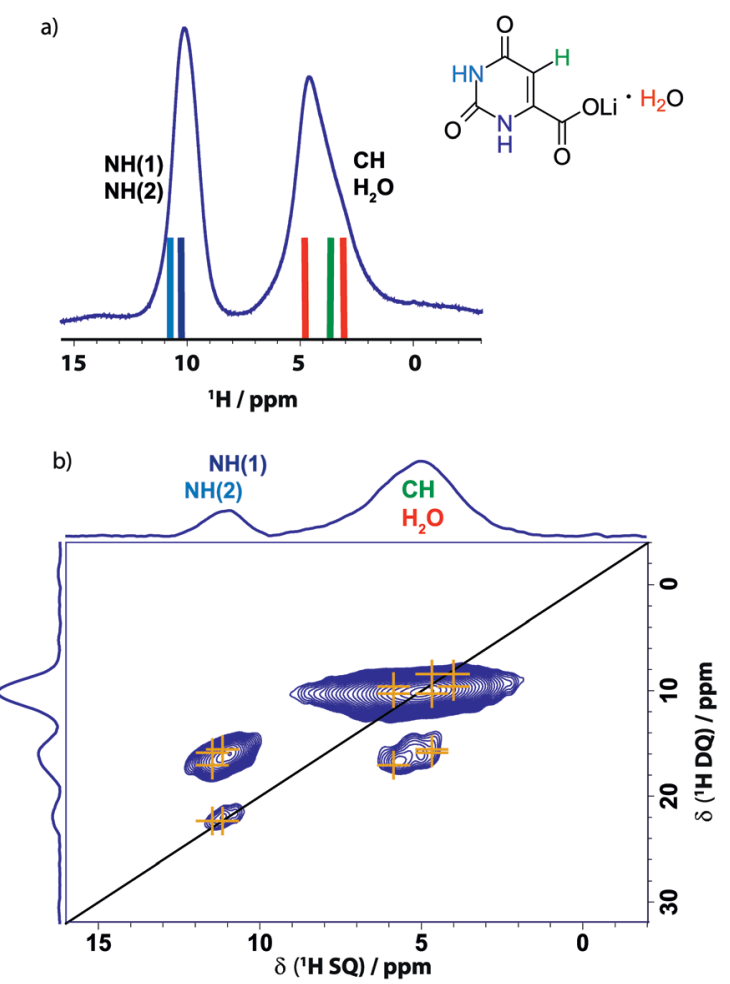

Fig. 2 (a) ${ }^{1} \mathrm{H}$ one pulse ( 8 transients were co-added for a recycle delay of $6 \mathrm{~s}$ ) and (b) ${ }^{1} \mathrm{H}(\mathrm{DQ})-{ }^{1} \mathrm{H}(\mathrm{SQ}) 2 \mathrm{D}$ NMR spectra of 2 recorded at $14.1 \mathrm{~T}$ and $56 \mathrm{kHz}$ MAS. For the DQ spectrum, one rotor period of BABA recoupling was used and 32 transients were co-added for each of 64 $t_{1}$ FIDs using a recycle delay of $2 \mathrm{~s}$, corresponding to a total experimental time of $1.2 \mathrm{~h}$. The base contour level is at $9 \%$ of the maximum height and skyline projections are presented. The GIPAW calculated chemical shifts are indicated using the colour-coding introduced in Scheme 1 in (a), while the orange crosses in (b) represent the GIPAW calculated chemical shifts. 
corresponds to a closest intermolecular proximity of $3.53 \AA$ between the two different $\mathrm{NH}$ protons in molecules within adjacent layers. This is to be compared to a closest intramolecular proximity of $4.11 \AA$. The orange crosses in Fig. 2 b correspond to GIPAW calculated ${ }^{1} \mathrm{H}$ chemical shifts; these are $11.5 \mathrm{ppm}$ and $11.2 \mathrm{ppm}$ for the two NH protons, i.e., corresponding to $\delta_{\mathrm{DQ}}=11.5+11.2=22.7 \mathrm{ppm}$ in the doublequantum dimension. Cross peaks corresponding to $\mathrm{NH}-\mathrm{NH}$, $\mathrm{NH}-\mathrm{CH}, \mathrm{NH}-\mathrm{H}_{2} \mathrm{O}$ and $\mathrm{CH}-\mathrm{H}_{2} \mathrm{O}$ as well as $\mathrm{H}_{2} \mathrm{O}-\mathrm{H}_{2} \mathrm{O}$ (intramolecular) proximities are also observed in Fig. 2 (see Table 1). Although there is spectral overlap, two distinct DQ peaks can be observed at $\delta_{\mathrm{DQ}}=11.1+5.7=16.8 \mathrm{ppm}$ as well as $\delta_{\mathrm{DQ}}=$ $11.1+5.0=16.1 \mathrm{ppm}$ and $\delta_{\mathrm{DQ}}=10.8+5.0=15.8 \mathrm{ppm}$ corresponding to close proximities between the $\mathrm{NH}(2)$ proton and the water proton (b) and both $\mathrm{NH}$ protons and the $\mathrm{CH}$ proton. This supports the observation of two distinct water proton chemical shifts - the GIPAW calculated values are 4.0 and $5.9 \mathrm{ppm}$, which is consistent with the tight incorporation of the water molecules within this network.

A series of other solid-state NMR measurements at different magnetic fields and MAS frequencies was also performed for 2. This includes one dimensional ${ }^{7} \mathrm{Li}$ direct excitation as well as ${ }^{13} \mathrm{C}$ and ${ }^{15} \mathrm{~N}$ cross polarization (CP) experiments at $11.7 \mathrm{~T}$ and $10 \mathrm{kHz}$ MAS. Furthermore, ${ }^{14} \mathrm{~N}-{ }^{1} \mathrm{H}$ HMQC ${ }^{50-53}$ data was obtained at $14.1 \mathrm{~T}$ and $59 \mathrm{kHz}$ MAS. These spectra, together with the assignments and comparison with GIPAW calculated data are shown in section S4.3 of the ESI.†

Additionally, an overview of the interactions within the crystal affecting each particular atom can be gained by comparing GIPAW calculated chemical shifts for the full crystal environment to those for an isolated molecule. ${ }^{54-57}$ For lithium orotate, an additional GIPAW calculation for a charged crystal structure without the lithium ion was performed. The net charge of -1 per unit cell was specified in the param input file for the NMR shielding calculation (see also section S5.3 in the ESI $\dagger$ ). This procedure allows a straightforward distinguishing between the contribution to the NMR chemical shift caused by the interactions with other orotate fragments in the network and the connecting individual lithium ions. Considering Fig. 3, the presence of the lithium ion affects all ${ }^{13} \mathrm{C}$ chemical shifts to a different extent, with the aromatic $\mathrm{CH}\left(\mathrm{C} 3, \Delta \delta_{\text {calc }}=6 \mathrm{ppm}\right)$ being the most affected. In this case, the effect of the lithium ion on the chemical shift domi-

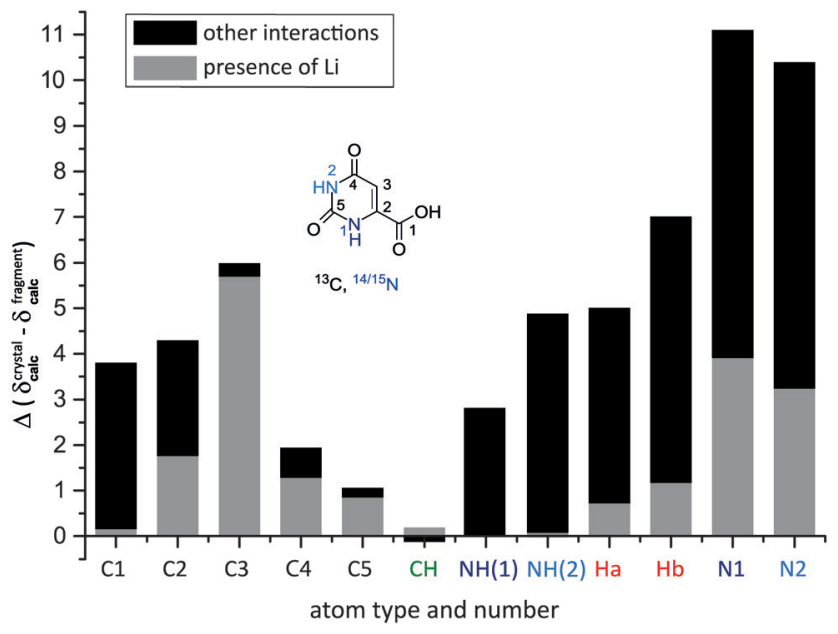

Fig. 3 Change of NMR chemical shifts (in ppm) as calculated using the GIPAW method for the full crystal structure and corresponding "fragments" consisting either of a full unit cell of $\mathbf{2}$ without the lithium atoms (grey) or an isolated orotate or water molecule (black).

nates, while other intermolecular contacts contribute less. As the water molecule is directly attached to the lithium ion, the presence of the lithium atom influences these ${ }^{1} \mathrm{H}$ chemical shifts the most, but still only by 0.7 and $1.2 \mathrm{ppm}$, whereas intermolecular hydrogen bonding has a much larger effect. In addition, there is a pronounced effect on the ${ }^{1} \mathrm{H}$ chemical shifts for the $\mathrm{NH}$ protons due to intermolecular hydrogen bonding. By contrast, the $\mathrm{CH}$ proton shows only a very small change between GIPAW calculations for the full crystal structure and an isolated molecule (both with and without the lithium ion).

NMR crystallography of orotic acid monohydrate (1) - the dynamic case

NMR crystallography was also used to study orotic acid monohydrate 1. Fig. 4a presents a ${ }^{1} \mathrm{H}(\mathrm{DQ})-{ }^{1} \mathrm{H}(\mathrm{SQ})$ NMR spectrum recorded at $14.1 \mathrm{~T}$ and fast spinning at $56 \mathrm{kHz}$ MAS (a ${ }^{14} \mathrm{~N}-{ }^{1} \mathrm{H}$ HMQC solid-state NMR spectrum recorded under the same conditions is presented in Fig. S9 of the ESI $\dagger$ ). While distinct proton resonances are resolved in the single-quantum dimension, an evident broadening of

Table $1{ }^{1} \mathrm{H}$ DQ correlations ${ }^{a}$ observed in Fig. $2 \mathrm{~b}$ for lithium orotate monohydrate, 2, together with the corresponding shortest distance

\begin{tabular}{|c|c|c|c|c|c|}
\hline Proton & $\delta_{\mathrm{SQ} \_}\left({ }^{1} \mathrm{H}\right) \mathrm{ppm}$ & Proton & $\delta_{\text {SQ_2 }}\left({ }^{1} \mathrm{H}\right) \mathrm{ppm}$ & $\delta_{\mathrm{DQ}}\left({ }^{1} \mathrm{H}\right) \mathrm{ppm}$ & Separation $^{b} / \AA$ \\
\hline $\mathrm{H}_{2} \mathrm{Oa}$ & 4.0 & $\mathrm{H}_{2} \mathrm{Ob}$ & 5.9 & 9.9 & 1.54 \\
\hline $\mathrm{CH}$ & 4.7 & $\mathrm{NH}(1)$ & 11.2 & 15.9 & 3.52 \\
\hline $\mathrm{CH}$ & 4.7 & $\mathrm{NH}(2)$ & 11.5 & 16.2 & 3.28 \\
\hline $\mathrm{H}_{2} \mathrm{Ob}$ & 5.9 & $\mathrm{NH}(2)$ & 11.5 & 17.4 & 2.60 \\
\hline $\mathrm{NH}(1)$ & 11.2 & $\mathrm{NH}(2)$ & 11.5 & 22.7 & 3.53 \\
\hline
\end{tabular}

${ }^{a}$ Intramolecular proximities are shown in italics. GIPAW calculated chemical shifts are stated (orange crosses in Fig. $2 \mathrm{~b}$ ). ${ }^{b} \mathrm{H}-\mathrm{H}$ distances from the DFT (CASTEP) geometry optimized structure. 


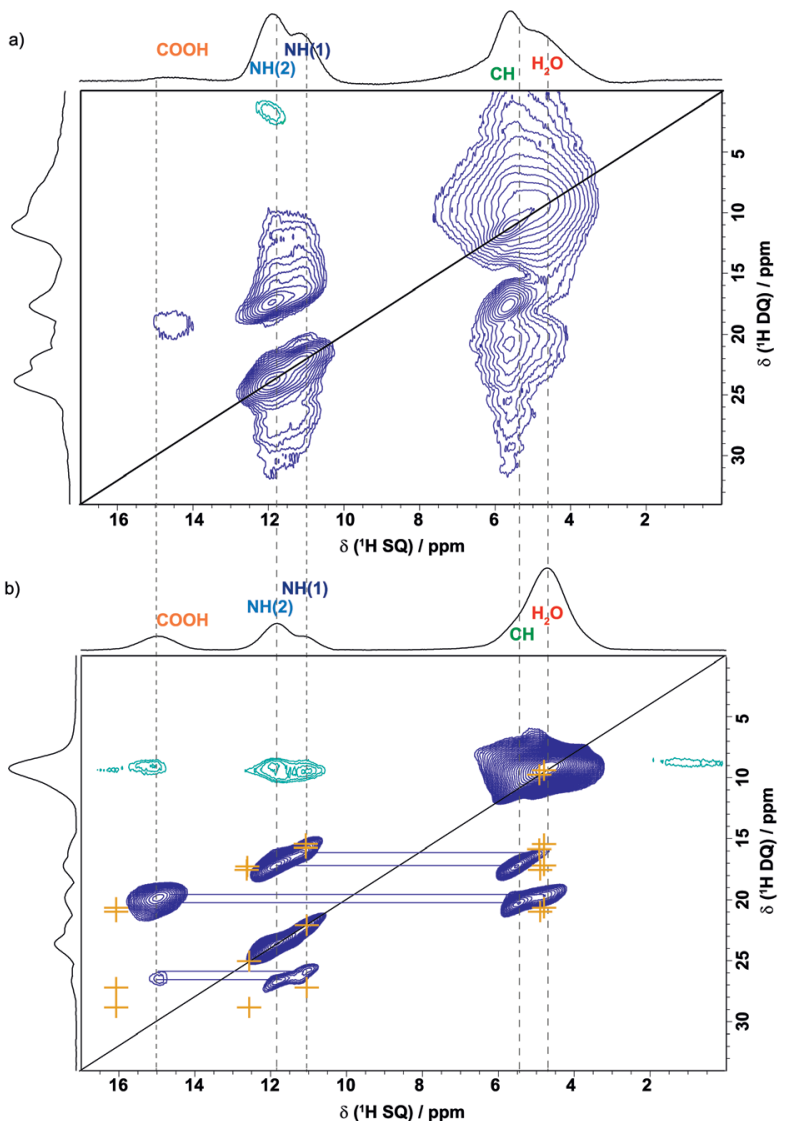

Fig. $4{ }^{1} \mathrm{H}(\mathrm{DQ})-{ }^{1} \mathrm{H}(\mathrm{SQ}) \quad \mathrm{NMR}$ correlation spectra of 1 (with skyline projections) recorded using one rotor period of $B A B A$ recoupling at (a) $14.1 \mathrm{~T}$ and $56 \mathrm{kHz}$ MAS, co-adding 16 transients for each of $154 t_{1}$ FIDs and (b) $20 \mathrm{~T}$ and $60 \mathrm{kHz}$ (with cooling applied to cancel the effect of frictional heating so as to achieve a sample temperature of $\sim 20{ }^{\circ} \mathrm{C}$ ), with eight transients co-added for each of $100 t_{1}$ FIDs. The recycle delay was (a) 30 and (b) $25 \mathrm{~s}$, corresponding to experimental times of (a) 20.5 and (b) $5.6 \mathrm{~h}$. The base contours are at (a) $9 \%$ and (b) $8 \%$ of the maximum height. In (b), orange crosses denote GIPAW calculated chemical shifts.

the resonances is observed, notably for the carboxylic acid and water molecule protons. A significant reduction in intensity is also evident for the carboxylic acid resonance. This indicates that dynamics (on the timescale of the NMR evolution periods) involving the $\mathrm{COOH}$ and $\mathrm{H}_{2} \mathrm{O}$ protons are occurring since it is known that motion leads to reduced ${ }^{1} \mathrm{H}$ DQ recoupling efficiency. ${ }^{58-61}$ Note that a ${ }^{1} \mathrm{H}$ DQ MAS spectrum of anhydrous orotic acid (see Fig. S10 in the ESI $\dagger$ ) recorded under the same experimental conditions does not show loss of signal intensity for the $\mathrm{COOH}$ resonance.

Fig. 5 presents a series of ${ }^{1} \mathrm{H}$ one-pulse NMR experiments recorded at $20 \mathrm{~T}$ for different MAS frequencies between 35 and $60 \mathrm{kHz}$. Taking into account sample heating due to MAS, ${ }^{62}$ this corresponds to sample temperatures of 25, 29, $35,40,45$ and $52{ }^{\circ} \mathrm{C}$ (in steps of $5 \mathrm{kHz}$ from 35 to $60 \mathrm{kHz}$ ). In the absence of dynamics, the ${ }^{1} \mathrm{H}$ linewidth in a multi-spin dipolar coupled network is expected to narrow with increasing

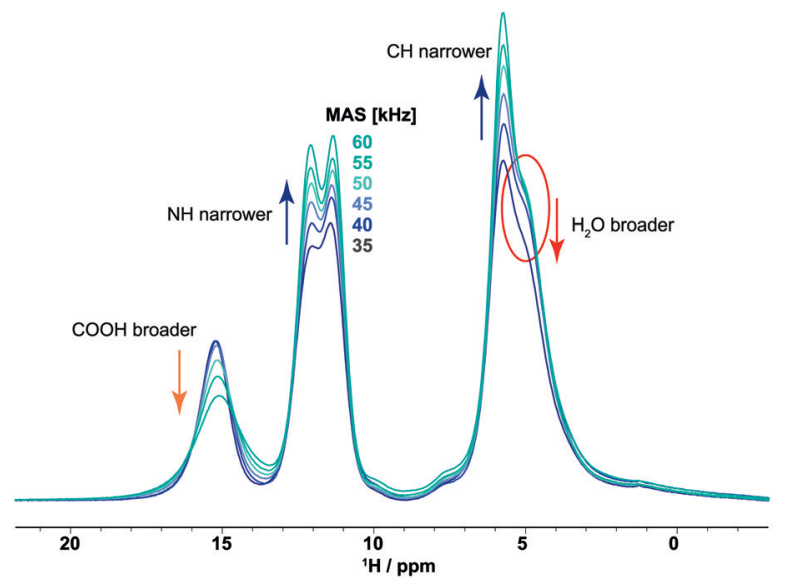

Fig. $5{ }^{1} \mathrm{H}$ NMR spectra of 1 recorded at $20 \mathrm{~T}$ and different MAS frequencies without any cooling. The $\mathrm{NH}$ and $\mathrm{CH}$ resonances expectedly narrow with increasing spinning frequency, while the $\mathrm{COOH}$ and $\mathrm{H}_{2} \mathrm{O}$ resonances broaden instead and also show a shift to lower ppm values because of the frictional heating at high MAS frequencies. In all experiments, 8 transients were co-added for a recycle delay of $25 \mathrm{~s}$.

MAS frequency: ${ }^{63,64}$ this is observed for the $\mathrm{NH}$ (11.8 and $11.1 \mathrm{ppm})$ and $\mathrm{CH}(5.4 \mathrm{ppm})$ resonances. However, as noted above, increasing the MAS frequency also increases the sample temperature via frictional heating, with this explaining the observed broadening upon increasing MAS frequency for both the $\mathrm{COOH}$ and $\mathrm{H}_{2} \mathrm{O}$ resonances. Water mobility in orotic acid cocrystals has been previously investigated by measuring the dielectric constant. ${ }^{65}$ Furthermore, Braun and co-workers performed crystal structure prediction (CSP) studies of orotic acid monohydrate $\mathbf{1}$ and its anhydrate form complemented by PXRD, thermal analysis, IR and Raman spectroscopy as well as $1 \mathrm{D}{ }^{1} \mathrm{H},{ }^{1} \mathrm{H}$ CRAMPS, ${ }^{1} \mathrm{H}^{1}{ }^{13} \mathrm{C}$ and ${ }^{1} \mathrm{H}-$ ${ }^{15} \mathrm{~N}$ CP MAS NMR experiments. ${ }^{66}$ Interestingly, CSP for the monohydrate (see Fig. 10 in ref. 64) produced several potential structures, an analysis of which revealed differences in the specific orientation of the water molecules, hinting at an explanation for the dynamics that we observe. Additionally, the water molecules act as a proton transfer bridge in this structure as has also been shown, for example, in other $\operatorname{IR}^{67}$ or NMR studies. ${ }^{68}$

In Fig. $4 \mathrm{~b}$, a ${ }^{1} \mathrm{H}(\mathrm{DQ}){ }^{1} \mathrm{H}(\mathrm{SQ})$ MAS spectrum of 1 recorded at a magnetic field strength of $20 \mathrm{~T}$ and $60 \mathrm{kHz}$ MAS is presented whereby cooling was applied to cancel the effect of frictional heating resulting in an effective sample temperature of $\sim 20{ }^{\circ} \mathrm{C}$. Comparing Fig. $4 \mathrm{a}$ and b, it is evident that cooling has led to a recovery of intensity for the $\mathrm{COOH}$ and $\mathrm{H}_{2} \mathrm{O}$ resonances. Of most interest is the absence of a $\mathrm{COOH}$ auto peak that would be observed for the more typical formation of a carboxylic acid dimer. ${ }^{68-71}$ Instead, as shown in Fig. 1, two water molecules interlink pairs of orotic acid molecules via $\mathrm{OH} \cdots \mathrm{O}$ intermolecular hydrogen bonds, with the two amine moieties also forming $\mathrm{NH} \cdots \mathrm{O}=\mathrm{C}$ intermolecular hydrogen bonds. In Fig. 4b, orange crosses denote DQ peak positions as predicted by GIPAW chemical shift calculations 
Table $2{ }^{1} \mathrm{H} \mathrm{DQ}$ correlations ${ }^{a}$ observed in Fig. $4 \mathrm{~b}$ for orotic acid monohydrate, 1, together with the corresponding shortest distance(s)

\begin{tabular}{|c|c|c|c|c|c|}
\hline Proton & $\delta_{\mathrm{SQ} \_}\left({ }^{1} \mathrm{H}\right) \mathrm{ppm}$ & Proton & $\delta_{\mathrm{SQ} \_2}\left({ }^{1} \mathrm{H}\right) \mathrm{ppm}$ & $\delta_{\mathrm{DQ}}\left({ }^{1} \mathrm{H}\right) \mathrm{ppm}$ & Separation $^{b} / \AA$ \\
\hline $\mathrm{CH}$ & 4.7 & $\mathrm{CH}$ & 4.7 & 9.4 & 3.11 \\
\hline $\mathrm{H}_{2} \mathrm{Ob}$ & 4.9 & $\mathrm{H}_{2} \mathrm{Ob}$ & 4.9 & 9.8 & 3.38 \\
\hline $\mathrm{H}_{2} \mathrm{Oa}$ & 4.7 & $\mathrm{NH}(1)$ & 11.1 & 15.8 & 3.35 \\
\hline $\mathrm{H}_{2} \mathrm{Ob}$ & 4.9 & $\mathrm{NH}(1)$ & 11.1 & 16.0 & $3.18,3.39$ \\
\hline $\mathrm{H}_{2} \mathrm{Oa}$ & 4.7 & $\mathrm{NH}(2)$ & 12.6 & 17.3 & 2.75 \\
\hline $\mathrm{CH}$ & 4.7 & $\mathrm{COOH}$ & 16.1 & 20.8 & $2.74,3.56$ \\
\hline $\mathrm{H}_{2} \mathrm{Ob}$ & 4.9 & $\mathrm{COOH}$ & 16.1 & 21.0 & $2.16,3.40$ \\
\hline $\mathrm{NH}(1)$ & 11.1 & $\mathrm{NH}(1)$ & 11.1 & 22.2 & 2.80 \\
\hline $\mathrm{NH}(2)$ & 12.6 & $\mathrm{NH}(2)$ & 12.6 & 25.2 & 2.31 \\
\hline $\mathrm{NH}(1)$ & 11.1 & $\mathrm{COOH}$ & 16.1 & 27.2 & 3.21 \\
\hline $\mathrm{NH}(2)$ & 12.6 & $\mathrm{COOH}$ & 16.1 & 28.8 & 3.14 \\
\hline
\end{tabular}

${ }^{a}$ Intramolecular proximities are shown in italics. GIPAW calculated chemical shifts are stated (orange crosses in Fig. $4 \mathrm{~b}$ ). ${ }^{b} \mathrm{H}-\mathrm{H}$ distances from the (CASTEP) geometry optimized structure.

- see Table 2 for a listing corresponding to $\mathrm{H}-\mathrm{H}$ proximities within $3.6 \AA$.

In this particular case, the two protons of the water molecule, which was shown to be less tightly bound by TGA measurements (Fig. S3\%), are no longer distinguishable in the spectrum despite cooling being employed to record the spectrum in Fig. $4 \mathrm{~b}$. In this context, note that the GIPAW calculated chemical shifts for the $\mathrm{CH}$ and both $\mathrm{H}_{2} \mathrm{O}$ protons are similar (all within 4.5 to $4.7 \mathrm{ppm}$ ) such that a clear peak separation cannot be expected. Additional solid-state NMR experiments performed at moderate field and spinning frequencies $(11.7 \mathrm{~T}, 10 \mathrm{kHz})$ allowed for unambiguous assignment of the heteronuclear $\left({ }^{13} \mathrm{C}\right.$ and $\left.{ }^{15} \mathrm{~N}\right)$ chemical shifts with good agreement with the GIPAW calculated chemical shifts (see ESI, $†$ Fig. S8 and S9).

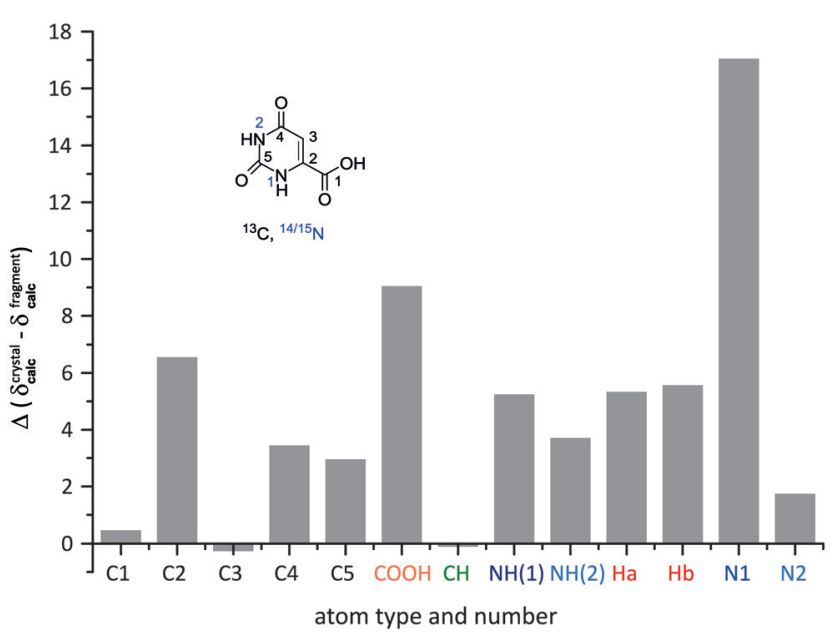

Fig. 6 Change of NMR chemical shifts (in ppm) as calculated using the GIPAW method for the full crystal structure of 1 and for an isolated orotic acid and an isolated water molecule. The values for the two isolated molecules were obtained in two separate calculations and without further geometry optimisation.
Finally, Fig. 6 presents a comparison of GIPAW NMR chemical shifts as calculated for the full crystal structure with that for an isolated orotic acid and an isolated water molecule. For orotic acid monohydrate 1, mostly minor changes are observed for the carbon atoms, while significant differences $\Delta \delta_{\text {(cryst-molecule) }}=3.7$ to $9 \mathrm{ppm}$ are found for all hydrogen atoms, except the $\mathrm{CH}$ proton. Large changes are observed for the $\mathrm{COOH}(\Delta \delta=9.1 \mathrm{ppm})$ and water protons $(\Delta \delta=5.3$ and $5.6 \mathrm{ppm}$ ) that are involved in $\mathrm{OH}^{\cdots} \mathrm{O}$ hydrogen bonding. For the $\mathrm{NH}$ protons, the molecule to crystal changes are $5.3 \mathrm{ppm}$ for $\mathrm{NH}(2)$ and $3.7 \mathrm{ppm}$ for $\mathrm{NH}(1)$, with these changes corresponding to $\mathrm{NH} \cdots \mathrm{O}$ hydrogen bonding distances of 1.73 and $1.84 \AA$ A, respectively.

So, overall and taking into account the dynamics found for orotic acid monohydrate, NMR crystallography is able to provide a detailed characterization of this compound.

NMR crystallography of magnesium orotate octahydrate (3) the challenging case

After being able to characterize the two hydrate structures belonging to class 1 and 3, the magnesium salt of orotic acid was studied to complete the picture. Crystallizing with eight water molecules per magnesium ion, this structure contains water molecules in ion associated positions (class 3), as well as in channels arranged along the crystallographic $c$-axis (class 2). As will be discussed subsequently, understanding this structure is significantly more complicated and presents a challenge for NMR crystallography and solid-state analysis more generally.

Fig. 7 presents one-pulse ${ }^{1} \mathrm{H}$ MAS NMR spectra of magnesium orotate 3. For 3 , the asymmetric unit (i.e., corresponding to the number of different sites observed in the NMR spectrum) includes half a magnesium octahedron, one "free" crystal water molecule and one orotate unit. Considering the as-synthesised sample, Fig. 7a compares the GIPAW calculated ${ }^{1} \mathrm{H}$ chemical shifts with the experimental ${ }^{1} \mathrm{H}$ MAS NMR 


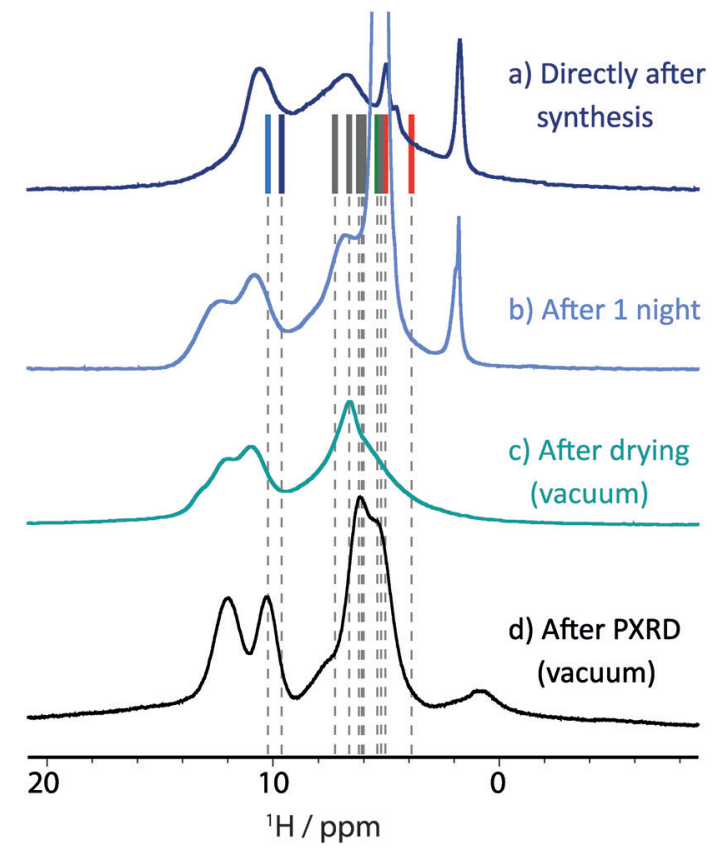

Fig. $7{ }^{1} \mathrm{H}$ NMR spectra of magnesium orotate octahydrate 3 recorded at $11.7 \mathrm{~T}$ and $25 \mathrm{kHz}$ MAS, (a) directly after sample preparation, (b) after one night of MAS and (c) after drying the sample under vacuum and repacking the rotor. Additionally, (d) the spectrum after evacuation monitored by PXRD (see Fig. 9 below) was recorded at $14.1 \mathrm{~T}$ and 60 $\mathrm{kHz}$ MAS. In all experiments, 16 transients were co-added for a recycle delay of $4 \mathrm{~s}$. For (a), vertical lines correspond to GIPAW calculated chemical shifts.

spectrum: there is reasonable agreement for the nitrogen bonded protons as well as the manifold of different water protons. The sharper features belong to more mobile groups and can be assigned to supernatant water $(\sim 5 \mathrm{ppm})^{72}$ as well as ion coordinated "free" $\left[\mathrm{Mg}\left(\mathrm{H}_{2} \mathrm{O}\right)_{6}\right]^{2+}$ octahedra $(\sim 2 \mathrm{ppm})$ as also found for other divalent ions $\left(\right.$ e.g. $\left.\mathrm{Ca}^{2+}\right) \cdot{ }^{73}$ Note that these signals are both filtered out in a double quantum experiment (see Fig. S15 in the ESI†).

Unfortunately, 3 was found to be unstable under prolonged magic angle spinning, as is evident from the spectrum recorded after one night of MAS (see Fig. 7b). At least one additional phase is now present with this being construed from the appearance in the ${ }^{1} \mathrm{H}$ MAS NMR spectrum of a second resonance for the amine functional groups $(>10$ $\mathrm{ppm})$. Furthermore, the signal previously assigned to supernatant water has significantly gained in intensity. This indicates that water previously incorporated in the crystalline structure is now uncoordinated, "free" water. Based on TGA analysis for as prepared 3 (see Fig. 8a), water would not be expected to escape from the structure until the temperature exceeds $75{ }^{\circ} \mathrm{C}$. While MAS causes sample heating, ${ }^{62}$ for MAS at $25 \mathrm{kHz}$ and input spinning gas at room temperature, the sample temperature is estimated to be $45{ }^{\circ} \mathrm{C}$, i.e., well below $75^{\circ} \mathrm{C}$. Thus, this is a rare case, where a structural change appears to originate from the centrifuging rather than the heating effect of MAS. For example, MAS was also found to be responsible for an altering of the polymorphic product a)

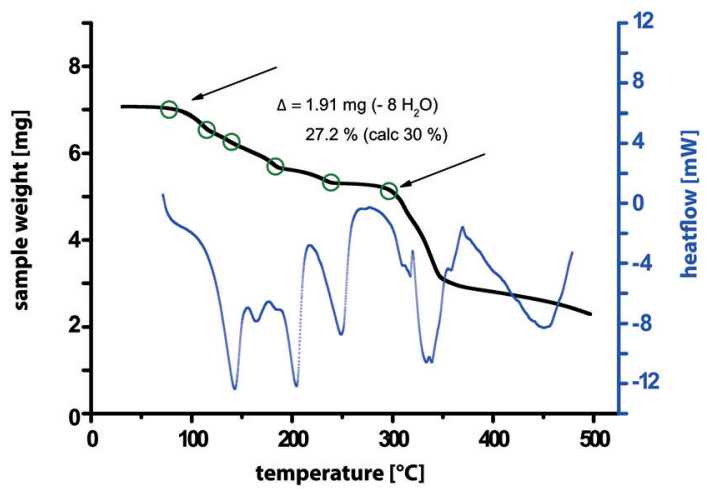

b)

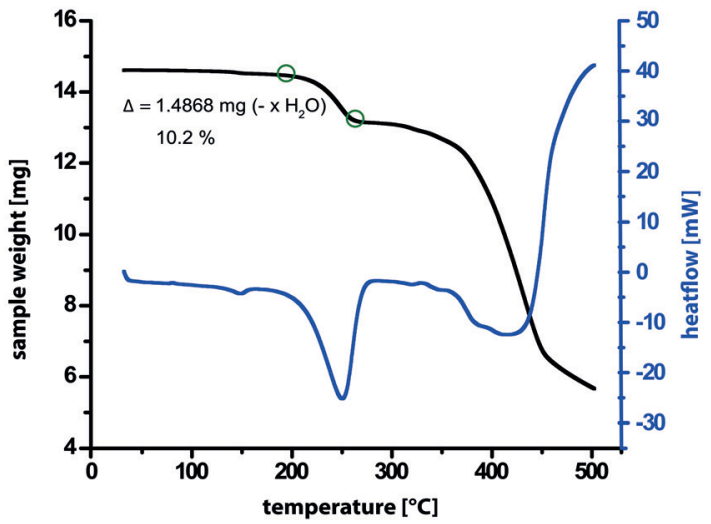

Fig. 8 TGA of 3 (a) directly after synthesis and (b) after evacuation in the PXRD diffractometer.

distribution in a dehydration study of sodium acetate trihydrate by $\mathrm{Xu}$ and Harris. ${ }^{74}$

The sample was then subjected to vacuum drying using a rotary oil pump capable of obtaining a vacuum of $0.1 \mathrm{mbar}$, to exclude the initial supernatant water as a source of instability. A ${ }^{1} \mathrm{H}$ MAS NMR spectrum of the resulting sample after drying is shown in Fig. 7c. Although the mobile water phases are observed to have been successfully eliminated, three different peaks can now be observed for the amine protons. Furthermore, a ${ }^{13} \mathrm{C}$ CP MAS NMR spectrum (see ESI, $†$ Fig. S14) shows a broadened signal for each carbon environment.

Given the changes revealed by ${ }^{1} \mathrm{H}$ MAS NMR, it is informative to consider the complementary insight provided by PXRD. As shown in Fig. S17 in the ESI, $\uparrow$ there is excellent agreement between a PXRD pattern for as-synthesised 3 and that simulated for the CSD-deposited structure (SIMZUJ). This PXRD pattern is shown in Fig. 9, where it is compared with the PXRD pattern of the sample after drying (i.e., corresponding to the ${ }^{1} \mathrm{H}$ solid-state NMR spectrum in Fig. 7c): notably, it is evident that there is an additional diffraction peak appearing at $9.4^{\circ} 2 \theta$. Although happening via a slow process, it was observed that the evacuated powder sample can partially reintegrate the water molecules upon storage. After storing the sample for 140 days under ambient conditions, it was again subjected to PXRD analysis. Fig. 9 shows that exposure to water in the air has resulted in the diffraction peak at $9.4^{\circ}$ being reduced in intensity, although the pattern has not returned to being the same as directly after synthesis. 


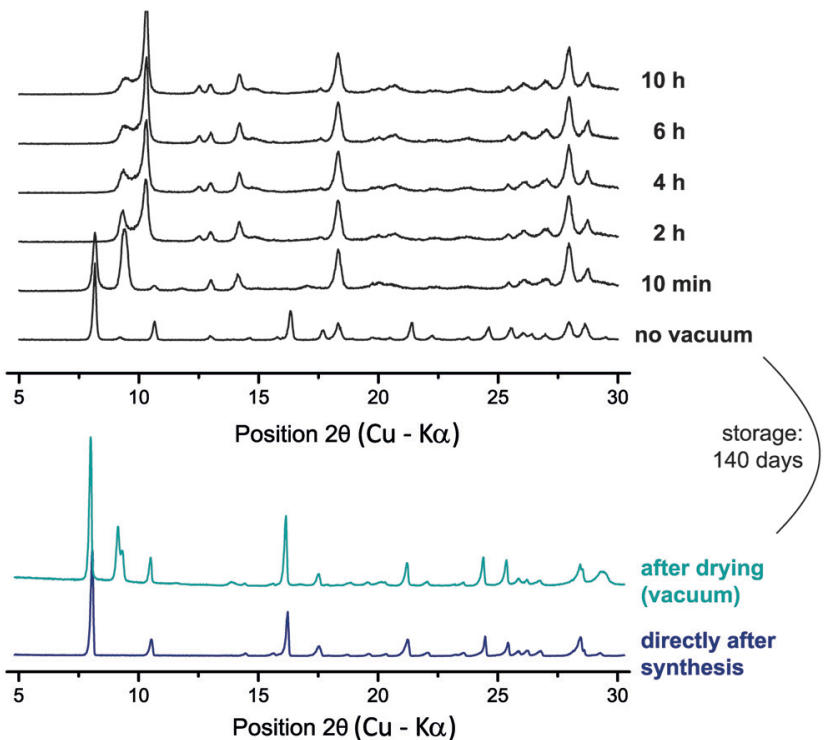

Fig. 9 PXRD patterns recorded for magnesium orotate octahydrate 3. The two diffraction patterns at the bottom correspond to those for the ${ }^{1} \mathrm{H}$ NMR spectra shown in Fig. $7 a$ and $\mathrm{c}$. After storage at ambient conditions for 140 days, an initial experiment without vacuum was recorded, then the vacuum pump was switched on and a series of PXRD diffraction patterns (each with a $2 \mathrm{~h}$ data collection duration) was recorded monitoring the changes upon evacuation.

Notably, there are other small additional diffraction peaks that were not observed in the PXRD pattern for the sample after vacuum drying.

The sample was subsequently evacuated inside the powder $\mathrm{X}$-ray diffractometer, which allows the sample chamber to be evacuated to around $10^{-3}$ mbar. After the recording of a first pattern after 10 minutes of evacuation, a series of diffraction patterns (taking $2 \mathrm{~h}$ each to collect the data) was recorded until no further changes in the diffraction pattern were observed. Directly after the evacuation was started, a decrease in intensity of the diffraction peaks at $8.2^{\circ} 2 \theta(h k l=100)$ and $10.6^{\circ} 2 \theta(h k l=110)$ is observed, while, simultaneously, the diffraction peak at $9.4^{\circ} 2 \theta$ is increasing. Over the course of the evacuation, the latter diffraction peak was observed to both decrease in intensity and broaden. The most dominant new feature is the intense peak observed at $10.3^{\circ} 2 \theta$. Furthermore, the diffraction peak at $13.0^{\circ} 2 \theta$ splits into two separate peaks. Apart from a small variation in symmetry, the changes observed for the 100 reflection could also indicate a reduction of the cell axis and thus a denser packing upon evacuation. Despite carrying out a longer experiment under vacuum after this series of experiments, an indexing of the PXRD pattern and hence a determination of the unit cell parameters was not possible. It was, however, possible to analyse the sample after evacuation in the powder X-ray diffractometer using TGA and solid-state NMR.

TGA data for the sample after monitoring the evacuation by PXRD is presented in Fig. 8b, allowing a comparison to the TGA data in Fig. 8a for as synthesised 3. While in Fig. 8a, a gradual stepwise loss of almost $30 \%$ of the total mass corresponding to eight molecules of water is observed (see Table S5 in the ESI $\dagger$ ), the TGA trace in Fig. 8a shows a one-step weight loss of only $10 \%$ at a considerably higher temperature (230-270 ${ }^{\circ} \mathrm{C}$ compared to $80-270{ }^{\circ} \mathrm{C}$ ). In both cases, further heating leads to decomposition of the sample. Therefore, for the sample after evacuation in the powder X-ray diffractometer, most of the water molecules have been removed from the structure, leaving only the most tightly bound ones with the highest dehydration temperature. For this structure, a difference in sample weight of $10 \%$ corresponds to a loss of two molecules of water (see Table S5 in the ESI $\dagger$ ), which are therefore deduced to remain in the structure after evacuation.

Additionally, a series of $1 \mathrm{D}$ and 2D solid-state MAS NMR spectra was recorded for this sample after evacuation in the powder X-ray diffractometer. As shown in Fig. 7d, two distinct peaks are now resolved in the $\mathrm{NH}$ region of the ${ }^{1} \mathrm{H}$ MAS a)

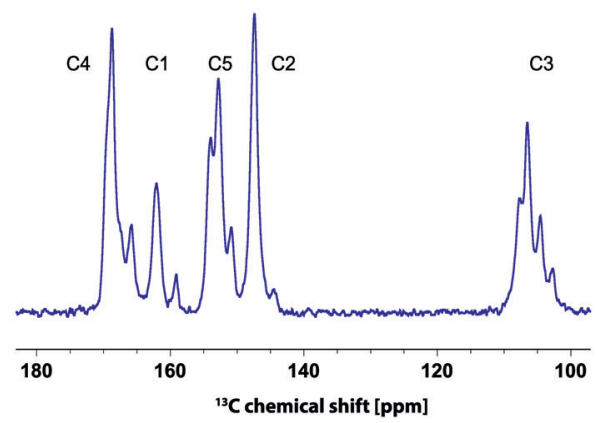

b)

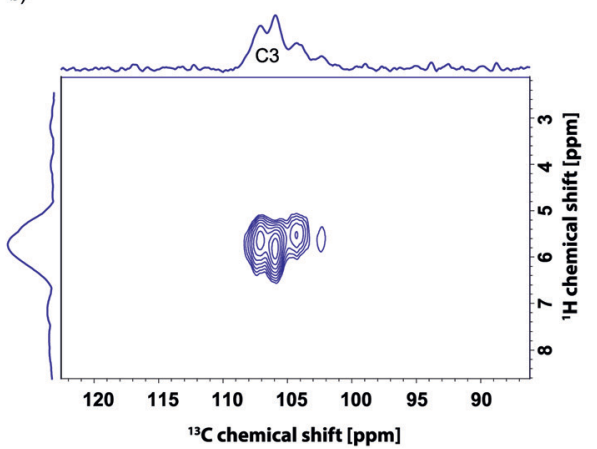

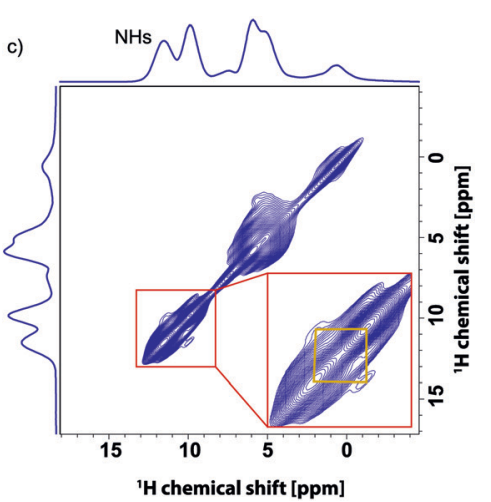

Fig. 10 Solid-state MAS NMR spectra of 3 after evacuation monitored by PXRD recorded at (a and b) 11.7 and (c) 14.1 T. (a) A ${ }^{13} \mathrm{C}$ CP MAS spectrum with 10240 co-added transients. (b) A ${ }^{13} \mathrm{C}-{ }^{1} \mathrm{H}$ refocused INEPT spectrum recorded with a spin-echo duration of $\tau=\tau^{\prime}=1.9 \mathrm{~ms}$. For both (a) and (b), the MAS frequency was $12.5 \mathrm{kHz}$ and the recycle delay was $3 \mathrm{~s}$. For (b), 128 transients were co-added for each of the $56 t_{1}$ FIDs corresponding to an experimental time of $6 \mathrm{~h}$. (c) A ${ }^{1} \mathrm{H}$ NOESY-like spin-diffusion MAS (60 kHz) spectrum recorded for a 5 ms mixing time. 16 transients were co-added for each of $256 t_{1}$ FIDs using a recycle delay of $1 \mathrm{~s}$, corresponding to an experimental time of $1.2 \mathrm{~h}$. The base contour level is at (b) $10 \%$ and (c) $4 \%$ of the maximum height. Skyline projections are shown for both $2 \mathrm{D}$ spectra. 
spectrum - note that a faster MAS frequency of $60 \mathrm{kHz}$ was used as compared to $25 \mathrm{kHz}$ for Fig. 7a to c, and an enhanced line narrowing is hence expected. ${ }^{63,64}$ As can be seen from the ${ }^{13} \mathrm{C}$ CP MAS spectrum in Fig. 10a, at least three to four narrow peaks are observed for each carbon resonance (e.g. C3). This is further evident from the ${ }^{13} \mathrm{C}-{ }^{1} \mathrm{H}$ refocused INEPT spectrum presented in Fig. 10b. These experimental observations can be explained by there being either a mixture of defined phases present or there being one phase, in which each of the orotate molecules in the unit cell is in a different environment. To investigate this, Fig. 10c shows a ${ }^{1} \mathrm{H}^{-1} \mathrm{H}$ NOESY-like spin-diffusion spectrum recorded for a short mixing time of $5 \mathrm{~ms}$. The observation of cross peak intensity between the two distinct $\mathrm{NH}$ resonances for such a short mixing time demonstrates that there are molecules in the sample with ${ }^{1} \mathrm{H}$ chemical shifts for the two $\mathrm{NH}$ groups in the same single molecule that correspond to the two separate ${ }^{1} \mathrm{H}$ resonances. A similar procedure was also successful in characterizing linker distributions in mixed-linker MOFs. ${ }^{75}$ It is to be noted though that the broad ${ }^{1} \mathrm{H}$ resonances do not preclude contributions from more than one phase to each peak.

The only crystal structure available for a magnesium orotate hydrate is for the case containing eight water molecules. Therefore, DFT calculations were used to consider possible structures consistent with our experimental observations of dihydrate formation. Our approach was to take the initial octahydrate crystal structure and remove different water molecules such that only two water molecules per $\mathrm{Mg}^{2+}$ orotate fragment remained. The resulting structures were then geometry optimized allowing the unit cell dimensions to vary using the CASTEP DFT code with a semi empirical dispersion correction scheme due to Tkatchenko and Scheffler. $^{76}$ Then NMR chemical shieldings were calculated for these structures using the GIPAW approach, hence allowing comparison, as shown in Fig. 11, with the experimental solid-state NMR data that has been presented above. A comparable procedure was successfully used by Ashbrook and co-workers to gain insight into the structure of hydrous wadsleyite, a magnesium silicate material. ${ }^{77}$

A ${ }^{1} \mathrm{H}$ one-pulse MAS spectrum (repeated from Fig. 7a) and the aromatic $\mathrm{CH}$ (C3) region of a ${ }^{13} \mathrm{C}$ CP MAS NMR spectrum of as synthesised 3 and after evacuation in the PXRD diffractometer are shown in Fig. 11a and b, respectively. Stick spectra representing GIPAW calculated chemical shifts are presented for the geometry-optimised crystal structure of magnesium orotate octahydrate in Fig. 11a and for a symmetric and an asymmetric DFT-derived dihydrate structures in Fig. 11c and d, respectively. These symmetric and asymmetric dihydrate structures are shown in Fig. 11g. The symmetric structure was generated by keeping only the channel water molecules in the structure, while the asymmetric structure corresponds to there being one Mg-coordinated and one channel water molecule in the structure. A geometry optimization was then carried out (with a difference in energy of $0.01 \mathrm{eV}$ per atom between the symmetric and asymmetric structures).
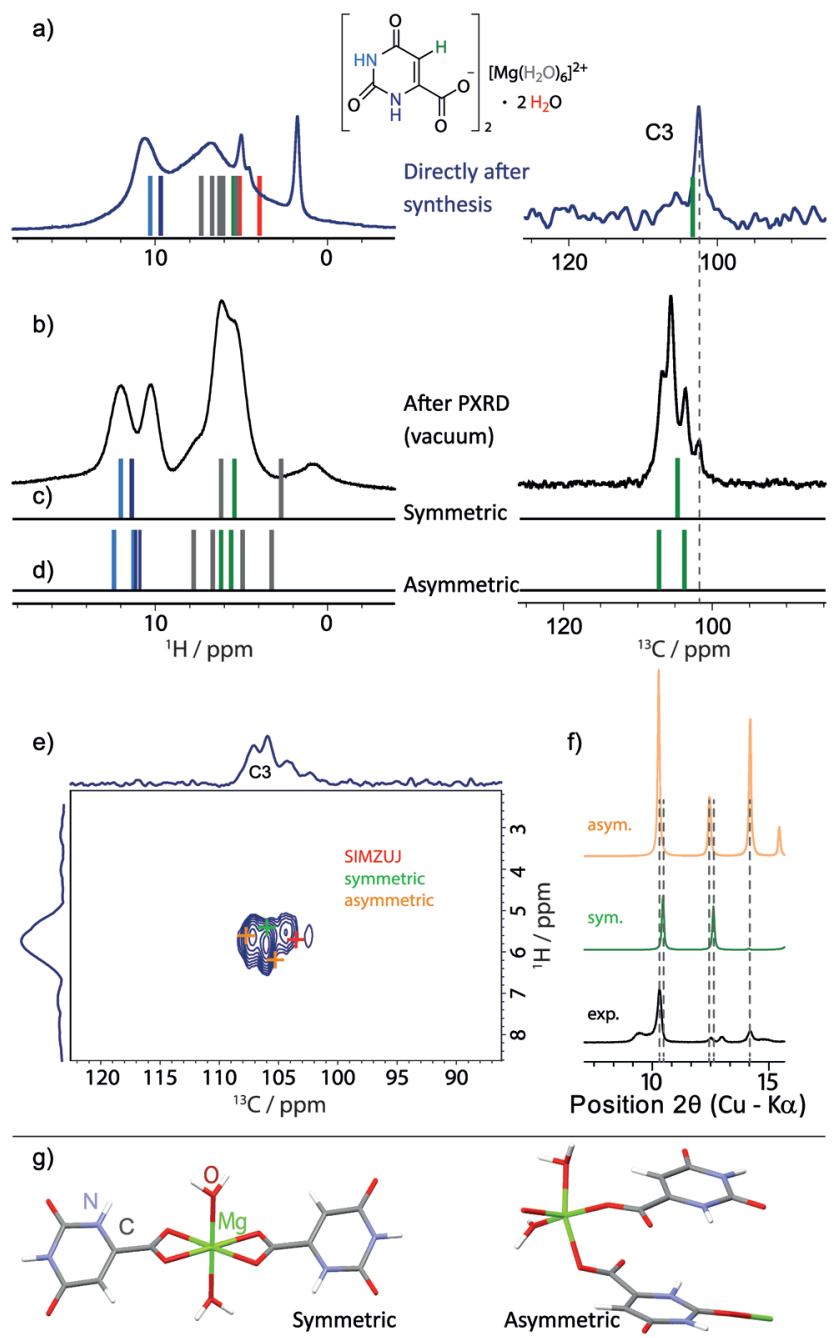

Fig. 11 (a and b) Experimental ${ }^{1} \mathrm{H}$ one-pulse MAS $(25 \mathrm{kHz}$, repeated from Fig. 7) and ${ }^{13} \mathrm{C} C P$ MAS NMR spectra (only the aromatic $\mathrm{CH}$ (C3) region is shown, 1024 transients were co-added for a recycle delay of $7 \mathrm{~s})$ recorded at $11.7 \mathrm{~T}$ of 3 (a) directly after synthesis and (b) after evacuation in the PXRD diffractometer. GIPAW (CASTEP) calculated chemical shifts are represented as vertical bars (colour coded by atom type, as used throughout this work) for (a) the geometry-optimised crystal structure of magnesium orotate octahydrate, (c) a symmetric and (d) an asymmetric dihydrate structure as obtained by DFT geometry optimisation. The ${ }^{13} \mathrm{C}-{ }^{1} \mathrm{H}$ refocused INEPT spectrum from Fig. $10 \mathrm{~b}$ is shown in (e) with coloured crosses indicating the peak positions based on GIPAW (CASTEP) calculations of the three structures. (f) Extract from the comparison between the corresponding experimental and simulated PXRD patterns (see Fig. S19 in ESI $\uparrow$ for the full diffraction patterns). The dihydrate structures are presented in (g), noting that the colour coding here corresponds to the usual convention of red for oxygen atoms and blue for nitrogen atoms.

Considering the ${ }^{13} \mathrm{C}$ aromatic $\mathrm{CH}$ (C3) chemical shifts, the lowest intensity peak in Fig. $11 \mathrm{~b}$ is assigned to a small amount of octahydrate. Importantly, the three GIPAW calculated ${ }^{13} \mathrm{C}$ aromatic $\mathrm{CH}$ (C3) chemical shifts for the symmetric and asymmetric dihydrate structures are at higher ppm values than for the octahydrate structure (see Fig. 11a, c and d); this is consistent with the observation of three new experimental peaks in Fig. 11b at higher ppm 
values. We thus hypothesise that the sample after evacuation is a mixture of symmetric and asymmetric dihydrate structures (as well as some octahydrate). Considering the ${ }^{1} \mathrm{H}$ chemical shifts, the GIPAW calculated values for the symmetric and asymmetric dihydrate structures in Fig. 11c and d are at higher ppm values than for the octahydrate structure in Fig. 11a, with this again being consistent with the change in the experimental spectrum between Fig. 11a and b. The observation of two experimental $\mathrm{NH}^{1} \mathrm{H}$ resonances in Fig. 11b is consistent with two distinct calculated ${ }^{1} \mathrm{H}$ chemical shifts for the two $\mathrm{NH}$ protons in the symmetric dihydrate structure and the separation of the four calculated ${ }^{1} \mathrm{H}$ chemical shifts (there are two molecules in the asymmetric unit cell) into two groups for the asymmetric dihydrate structure; this also explains the observation of cross peak intensity in the ${ }^{1} \mathrm{H}^{-}{ }^{1} \mathrm{H}$ NOESY-like spin-diffusion spectrum in Fig. 10c. The assumption is further supported by the good agreement of the GIPAW (CASTEP) calculated cross peak positions for the three structures overlaid with the experimental ${ }^{13} \mathrm{C}-{ }^{1} \mathrm{H}$ refocused INEPT spectrum (repeated from Fig. 10b) in Fig. 11e.

It is noted that comparison of the simulated PXRD patterns for the proposed structural models with the experimental data yields moderate agreement with respect to the number and position of the observed diffraction peaks at low $2 \theta$ angles (Fig. 11f, for a complete comparison, see Fig. S19 in the ESI $\dagger$ ). For larger $2 \theta$ angles, there is poor agreement - this is not surprising given that the PXRD peak positions are very sensitive to the unit cell parameters, which is also discussed in the recent work by Leclaire et $a .^{78}$ In their study, DFTderived structures consistent with extensive experimental solid-state NMR data for the analysed complex organic framework could be identified, however, it was not possible to fit an experimental PXRD pattern starting with the model structures since small changes in the unit cell parameters can result in significant differences in the PXRD diffraction peak positions. Although this approach is not unambiguous with there being a large space of possible structures, it still offers a valuable, first insight into the possible structures and gives useful indications to start understanding even for more complicated structures with a complex dehydration behaviour.

\section{Conclusions}

Three examples from the abundant group of hydrates showing a very diverse behaviour have been investigated by NMR crystallography in combination with PXRD and TGA. The lithium salt as a starting point proved to be a very stable model system with the water being tightly incorporated into the network of interactions. Thus, different environments for the two protons of the water molecule could be distinguished and theoretical and experimental data match well. Slowly decreasing the strength of interaction to the water molecules, orotic acid monohydrate could be shown to be partly mobile with respect to the acid and water positions, with this experimental finding being in line with a previous crystal structure prediction study by Braun and co-workers. ${ }^{66}$ Taking this into account, again good agreement between experiment and theory is possible. Finally, it was possible to start collecting evidence to understand the more complicated hydrate of magnesium orotate. With a multitude of water environments involved in interactions of varying strength and a complex dehydration behaviour for the octahydrate, this sample was found to be unstable under MAS conditions. A stable sample could only be obtained after evacuation monitored by PXRD and a series of techniques, solid-state NMR, DFT calculations and PXRD as well as TGA measurements, allowed a first understanding of the previously uncharacterised structures of magnesium orotate dihydrate.

Hydrates and dehydration behaviour are still not fully understood and there is a lot to learn. Rather than choosing an indirect approach via attached hetero nuclei only, solid-state NMR with proton detection ${ }^{79-82}$ is a powerful tool to directly monitor the hydrogen bonding $\mathrm{NH}$, aromatic $\mathrm{CH}$ and water environments. The combination with first-principles DFT calculations in an NMR crystallography approach is demonstrated for the present examples, one from each class of hydrates. In future work, it would be interesting to consider other hydrate systems so as to deduce common features and relate them to underlying structural properties.

\section{Experimental \& computational details}

\section{Synthetic procedures}

Orotic acid monohydrate was purchased from SigmaAldrich ${ }^{\circledR}$ (Gillingham, U.K.) and used as received for both structural characterization and synthesis of the corresponding lithium and magnesium salts. The synthesis followed the general procedure published by Schmidbaur and coworkers. $^{37}$ However, the low solubility of orotic acid in water necessitated some minor changes to the original protocol. Instead of preparing suspensions of orotic acid in water and then adding the corresponding metal hydroxide at room temperature, the water was warmed up to $70{ }^{\circ} \mathrm{C}$ and the hydroxides where added alternatingly with the orotic acid. The solutions were then heated to $90{ }^{\circ} \mathrm{C}$, stirred for $30 \mathrm{~min}$ and stored in the fridge for crystallisation. The reaction products were analysed by PXRD, IR and TGA measurements to ensure the desired product had formed.

\section{Analytical tools}

A Panalytical X-Pert Pro MPD diffractometer equipped with a curved Johansson monochromator giving pure focussed $\mathrm{Cu}$ $K_{\alpha 1}$ radiation and a solid-state PiXcel detector was used to check for phase purity of the starting material and to confirm the successful synthesis of the lithium and magnesium salt. Monitoring of the magnesium orotate powder X-ray diffraction pattern under vacuum was carried out using a Bruker D5005 diffractometer with $\mathrm{Cu} \mathrm{K}_{\alpha}$ radiation, standard BraggBrentano geometry and a diffracted beam graphite monochromator. The diffractometer is equipped with an Oxford Cryosystems Phenix low temperature stage to perform 
experiments at non-ambient conditions, i.e. under vacuum. All PXRD experiments were carried out at room temperature.

Infrared spectra of the starting material and the synthesized compounds were recorded as solid samples on a Bruker ALPHA FT-IR Spectrometer.

Thermogravimetric analysis (TGA) was performed using a Mettler-Toledo DSC1-400 instrument. 7-9 mg of each compound was placed into a $40 \mu \mathrm{L}$ aluminium sample pan, which was heated from 25 to $500{ }^{\circ} \mathrm{C}$ at a constant heating rate of $10{ }^{\circ} \mathrm{C}$ per minute.

\section{Solid-state NMR}

Solid-state NMR experiments were performed at ${ }^{1} \mathrm{H}$ Larmor frequencies of 500, 600 and $850 \mathrm{MHz}$ using Bruker Avance III (500 and 850) and II+ (600) spectrometers. All ${ }^{13} \mathrm{C}$ experiments were performed at $500 \mathrm{MHz}$ using a Bruker $4 \mathrm{~mm}$ triple-resonance MAS probe operating in double-resonance mode. Fast MAS experiments were performed using a $2.5 \mathrm{~mm}$ triple-resonance probe operating in double-resonance mode at $500 \mathrm{MHz}$ or a $1.3 \mathrm{~mm}$ triple-resonance probe operating in double-resonance mode at 600 and $850 \mathrm{MHz}$. In all experiments, the ${ }^{1} \mathrm{H} 90^{\circ}$ pulse length was of duration $2.5 \mu \mathrm{s}$.

For the ${ }^{1} \mathrm{H}$ double-quantum experiments, one rotor period of the $\mathrm{BABA}^{48,49}$ recoupling sequence was used for the excitation and reconversion of DQ coherence. A nested 16-step phase cycle was used to select $\Delta p= \pm 2$ on the DQ excitation pulses ( 4 steps) and $\Delta p=-1$ ( 4 steps) on the $z$-filter $90^{\circ}$ pulse, where $p$ is the coherence order. The $t_{1}$ increment was set equal to the rotor period (the reciprocal of the MAS frequency) and the States-TPPI method was used to achieve sign discrimination in $F_{1}$.

In experiments with ${ }^{13} \mathrm{C}$ detection, SPINAL64 (ref. 83) heteronuclear decoupling was applied during acquisition at a ${ }^{1} \mathrm{H}$ nutation frequency of $100 \mathrm{kHz}$. In ${ }^{1} \mathrm{H}^{-}{ }^{13} \mathrm{C}$ crosspolarization (CP) MAS experiments, a nested 8-step phase cycle was used to select $\Delta p= \pm 2$ on the initial ${ }^{1} \mathrm{H}$ excitation pulse, while the phase of the ${ }^{13} \mathrm{C}$ spinlock pulse cycled through $(x-x y-y)$ with the receiver phase following.

For the $2 \mathrm{D}{ }^{13} \mathrm{C}-{ }^{1} \mathrm{H}$ refocused INEPT experiment, ${ }^{84}$ eDUMBO- $1_{22}$ (ref. 85 and 86) homonuclear decoupling was used during the proton evolution period and the $\tau$ and $\tau^{\prime}$ spin-echo $(\tau / 2-\pi-\tau / 2)$ durations. The length of the eDUMBO$1_{22}$ cycle was $32 \mu \mathrm{s}$, with 320 divisions of $100 \mathrm{~ns}$ each. The pre-pulse duration was $1.2 \mu \mathrm{s}$. A scaling factor in $F_{1}$ of 1.6 was used. A 16-step phase cycle as described in the original publication $^{84}$ was used. The States method was used to achieve sign discrimination in $F_{1}$.

${ }^{13} \mathrm{C}$ and ${ }^{1} \mathrm{H}$ chemical shifts are referenced to TMS using L-alanine at natural abundance as a secondary reference (177.8 $\mathrm{ppm}$ for the higher $\mathrm{ppm}{ }^{13} \mathrm{C}$ resonance and $1.1 \mathrm{ppm}$ for the lower $\mathrm{ppm}{ }^{1} \mathrm{H}$ resonance).

\section{Calculations}

Calculations were performed using the CASTEP code, ${ }^{25}$ academic release version 8.0. For all geometry optimisations and
NMR chemical shielding calculations using the GIPAW method, ${ }^{24,26}$ the PBE exchange correlation was used. ${ }^{87} \mathrm{~A}$ maximum cut-off energy of $800 \mathrm{eV}$ was used for the employed plane wave basis set with ultra-soft pseudopotentials. ${ }^{88} \mathrm{~A}$ Monkhorst-Pack grid for sampling over the Brillouin zone with minimum sample spacing $0.1 \times 2 \pi \AA^{-1}$ was used. Geometry optimizations with the unit cell parameters fixed started from the corresponding single crystal X-ray structures (CSD codes: OROTAC01, SIMZOD01, SIMZUJ). The forces, energies and displacements were converged to better than $0.05 \mathrm{eV} \AA^{-1}$, $0.00002 \mathrm{eV}$, and $0.001 \AA$, respectively. For the magnesium orotate dihydrate model structures, all water molecules except for two per $\mathrm{Mg}^{2+}$ fragment were deleted. Prior to the calculation of NMR parameters, the resulting structures were fully geometry optimized by also allowing the unit cell parameters to vary and employing a semi empirical dispersion correction scheme according to Tkatchenko and Scheffler. ${ }^{76}$ NMR output obtained herein was further handled and visualized using the Magresview environment. ${ }^{89}$ For a crystal vs. molecule/fragment comparison, an additional NMR calculation has to be performed: a single molecule from the already fully geometry optimized structure is kept in the unit cell, which is also increased by $\sim 5 \AA$ in each direction. Thereby it is assured that this molecule is no longer in proximity to any neighbouring molecules. Subsequently, another set of NMR parameters can be calculated. In the specific case of molecular fragments carrying a charge, the particular charge was specified in the param-file (see section 5.3 in the ESI $\dagger$ ). It is to be emphasised that no further geometry optimisation was carried out.

\section{Acknowledgements}

This work was supported by a Feodor Lynen Research Fellowship of the Alexander von Humboldt Foundation and a Newton International Fellowship of the Royal Society (A.-C. P). The UK $850 \mathrm{MHz}$ solid-state NMR Facility used in this research was funded by EPSRC and BBSRC (contract reference PR140003), as well as the University of Warwick including via part funding through Birmingham Science City Advanced Materials Projects 1 and 2 supported by Advantage West Midlands (AWM) and the European Regional Development Fund (ERDF). Collaborative assistance from the $850 \mathrm{MHz}$ Facility Manager (Dr. Dinu Iuga, University of Warwick) is acknowledged. Computational facilities were provided by the MidPlus Regional Centre of Excellence for Computational Science, Engineering and Mathemtatics, under EPSRC grant EP/K000128/ 1 , and by the University of Warwick Scientific Computing Research Technology Platform. We also thank David Hammond (Department of Physics, University of Warwick) and Dr. Andrew Marsh (Department of Chemistry, University of Warwick) for carrying out the TGA measurements and for access to (vacuum drying) laboratory equipment, respectively. Furthermore, we thank Prof. Kenneth Harris and Dr. Colan Hughes for helpful discussions. The experimental and calculated data for this study are provided as a supporting dataset 
from WRAP, the Warwick Research Archive Portal at http:// wrap.warwick.ac.uk/83544.

\section{Notes and references}

1 R. K. Khankari and D. J. W. Grant, Thermochim. Acta, 1995, 248, 61-79.

2 A. Jørgensen, J. Rantanen, M. Karjalainen, L. Khriachtchev, E. Räsänen and J. Yliruusi, Pharm. Res., 2002, 19, 1285-1291.

3 H. P. Stahl, The problems of drug interactions with excipients in Towards better safety of drugs and pharmaceutical products, Elsevier/North-Holland Biomedical Press, 1980.

4 H. D. Clarke, K. K. Arora, H. Bass, P. Kavuru, T. T. Ong, T. Pujari, L. Wojtas and M. J. Zaworotko, Cryst. Growth Des., 2010, 10, 2152-2167.

5 S. R. Vippagunta, H. G. Brittain and D. J. W. Grant, Adv. Drug Delivery Rev., 2001, 48, 3-26.

6 U. J. Griesser, in Polymorphism, Wiley-VCH Verlag GmbH \& Co. KGaA, 2006, ch. 8, pp. 211-233, DOI: 10.1002/ 3527607889 .

7 H. G. Brittain, Polymorphism in Pharmaceutical Solids, CRC Press, 2nd edn, 2009.

8 R. K. Harris, Solid State Sci., 2004, 6, 1025-1037.

9 B. Elena, G. Pintacuda, N. Mifsud and L. Emsley, J. Am. Chem. Soc., 2006, 128, 9555-9560.

10 S. M. Reutzel-Edens, in Engineering of Crystalline Materials Properties: State of the Art in Modeling, Design and Applications, ed. J. J. Novoa, D. Braga and L. Addadi, Springer, Netherlands, Dordrecht, 2008, pp. 351-374, DOI: 10.1007/978-1-4020-6823-2_17.

11 R. K. Harris, R. E. Wasylishen and M. J. Duer, NMR Crystallography, John Wiley \& Sons, 2010.

12 S. P. Brown, Solid State Nucl. Magn. Reson., 2012, 41, 1-27.

13 S. E. Ashbrook and D. McKay, Chem. Commun., 2016, 52, 7186-7204.

14 M. Skotnicki, D. C. Apperley, J. A. Aguilar, B. Milanowski, M. Pyda and P. Hodgkinson, Mol. Pharmaceutics, 2016, 13, 211-222.

15 G. W. Stockton, R. Godfrey, P. Hitchcock, R. Mendelsohn, P. C. Mowery, S. Rajan and A. F. Walker, J. Chem. Soc., Perkin Trans. 2, 1998, 2061-2072.

16 B. E. Padden, M. T. Zell, Z. Dong, S. A. Schroeder, D. J. W. Grant and E. J. Munson, Anal. Chem., 1999, 71, 3325-3331.

17 L. Mafra, S. M. Santos, R. Siegel, I. Alves, F. A. Almeida Paz, D. Dudenko and H. W. Spiess, J. Am. Chem. Soc., 2012, 134, 71-74.

18 D. E. Braun, L. H. Koztecki, J. A. McMahon, S. L. Price and S. M. Reutzel-Edens, Mol. Pharmaceutics, 2015, 12, 3069-3088.

19 J. A. Fernandes, M. Sardo, L. Mafra, D. Choquesillo-Lazarte and N. Masciocchi, Cryst. Growth Des., 2015, 15, 3674-3683.

20 M. Sardo, S. M. Santos, A. A. Babaryk, C. López, I. Alkorta, J. Elguero, R. M. Claramunt and L. Mafra, Solid State Nucl. Magn. Reson., 2015, 65, 49-63.

21 D. Lüdeker and G. Brunklaus, Solid State Nucl. Magn. Reson., 2015, 65, 29-40.
22 A. Abraham, D. C. Apperley, S. J. Byard, A. J. Ilott, A. J. Robbins, V. Zorin, R. K. Harris and P. Hodgkinson, CrystEngComm, 2016, 18, 1054-1063.

23 D. M. Pisklak, M. A. Zielińska-Pisklak, Ł. Szeleszczuk and I. Wawer, J. Pharm. Biomed. Anal., 2016, 122, 81-89.

24 C. J. Pickard and F. Mauri, Phys. Rev. B: Condens. Matter Mater. Phys., 2001, 63, 245101.

25 S. J. Clark, M. D. Segall, C. J. Pickard, P. J. Hasnip, M. I. J. Probert, K. Refson and M. C. Payne, Z. Kristallogr., 2005, 220, 567.

26 J. R. Yates, C. J. Pickard and F. Mauri, Phys. Rev. B: Condens. Matter Mater. Phys., 2007, 76, 024401.

27 K. R. Geiss, N. Stergiou, Jester, H. U. Neuenfeld and H. G. Jester, Cardiovasc. Drugs Ther., 1998, 12, 153-156.

28 G. Jasmin and L. Proschek, Cardiovasc. Drugs Ther., 1998, 12, 189-195.

29 F. Rosenfeldt, S. Richards, Z. Lin, S. Pepe and R. J. Conyers, Cardiovasc. Drugs Ther., 1998, 12, 159-170.

30 M. A. Laskar and M. D. Choudhury, World J. Pharm. Sci., 2015, 4, 1248-1257.

31 D. F. Smith, Br. J. Pharmacol., 1976, 56, 399-402.

32 M. Gitlin and M. A. Frye, Bipolar Disord., 2012, 14, 51-65.

33 M. T. McCann, M. M. Thompson, I. C. Gueron and M. Tuchman, Clin. Chem., 1995, 41, 739-743.

34 R. A. Wevers, U. F. H. Engelke, S. H. Moolenaar, C. Bräutigam, J. G. N. de Jong, R. Duran, R. A. de Abreu and A. H. van Gennip, Clin. Chem., 1999, 45, 539-548.

35 N. Jacquel, K. Tajima, N. Nakamura, T. Miyagawa, P. Pan and Y. Inoue, J. Appl. Polym. Sci., 2009, 114, 1287-1294.

36 A. Tsui and C. W. Frank, Polymer, 2014, 55, 6364-6372.

37 I. Bach, O. Kumberger and H. Schmidbaur, Chem. Ber., 1990, 123, 2267-2271.

38 F. Takusagawa and A. Shimada, Bull. Chem. Soc. Jpn., 1973, 46, 2011-2019.

39 G. Portalone, Acta Crystallogr., Sect. E: Struct. Rep. Online, 2008, 64, 0656.

40 M. Lutz, Acta Crystallogr., Sect. E: Struct. Rep. Online, 2001, 57, m103-m105.

41 C. E. Housecroft and A. G. Sharpe, Inorganic Chemistry, Pearson Prentice Hall, 2005.

42 K. A. Strohfeldt, Essentials of Inorganic Chemistry: For Students of Pharmacy, Pharmaceutical Sciences and Medicinal Chemistry, Wiley, 2015.

43 R. K. Harris, P. Hodgkinson, C. J. Pickard, J. R. Yates and V. Zorin, Magn. Reson. Chem., 2007, 45, S174-S186.

44 C. Bonhomme, C. Gervais, F. Babonneau, C. Coelho, F. Pourpoint, T. Azaïs, S. E. Ashbrook, J. M. Griffin, J. R. Yates, F. Mauri and C. J. Pickard, Chem. Rev., 2012, 112, 5733-5779.

45 C. J. Pickard, E. Salager, G. Pintacuda, B. Elena and L. Emsley, J. Am. Chem. Soc., 2007, 129, 8932-8933.

46 A. L. Webber, B. Elena, J. M. Griffin, J. R. Yates, T. N. Pham, F. Mauri, C. J. Pickard, A. M. Gil, R. Stein, A. Lesage, L. Emsley and S. P. Brown, Phys. Chem. Chem. Phys., 2010, 12, 6970-6983. 
47 S. P. Brown, Prog. Nucl. Magn. Reson. Spectrosc., 2007, 50, 199-251.

48 W. Sommer, J. Gottwald, D. E. Demco and H. W. Spiess, J. Magn. Reson., Ser. A, 1995, 113, 131-134.

49 I. Schnell, A. Lupulescu, S. Hafner, D. E. Demco and H. W. Spiess, J. Magn. Reson., 1998, 133, 61-69.

50 S. Cavadini, S. Antonijevic, A. Lupulescu and G. Bodenhausen, J. Magn. Reson., 2006, 182, 168-172.

51 Z. Gan, J. P. Amoureux and J. Trébosc, Chem. Phys. Lett., 2007, 435, 163-169.

52 S. Cavadini, Prog. Nucl. Magn. Reson. Spectrosc., 2010, 56, 46-77.

53 A. S. Tatton, J. P. Bradley, D. Iuga and S. P. Brown, Z. Phys. Chem., 2012, 226, 1187-1203.

54 J. R. Yates, T. N. Pham, C. J. Pickard, F. Mauri, A. M. Amado, A. M. Gil and S. P. Brown, J. Am. Chem. Soc., 2005, 127, 10216-10220.

55 J. Schmidt, A. Hoffmann, H. W. Spiess and D. Sebastiani, J. Phys. Chem. B, 2006, 110, 23204-23210.

56 A.-C. Uldry, J. M. Griffin, J. R. Yates, M. Pérez-Torralba, M. D. Santa María, A. L. Webber, M. L. L. Beaumont, A. Samoson, R. M. Claramunt, C. J. Pickard and S. P. Brown, J. Am. Chem. Soc., 2008, 130, 945-954.

57 A. L. Webber, L. Emsley, R. M. Claramunt and S. P. Brown, J. Phys. Chem. A, 2010, 114, 10435-10442.

58 S. P. Brown, I. Schnell, J. D. Brand, K. Mullen and H. W. Spiess, Phys. Chem. Chem. Phys., 2000, 2, 1735-1745.

59 G. R. Goward, M. F. H. Schuster, D. Sebastiani, I. Schnell and H. W. Spiess, J. Phys. Chem. B, 2002, 106, 9322-9334.

60 Y. J. Lee, B. Bingöl, T. Murakhtina, D. Sebastiani, W. H. Meyer, G. Wegner and H. W. Spiess, J. Phys. Chem. B, 2007, 111, 9711-9721.

61 Ü. Akbey, R. Graf, Y. G. Peng, P. P. Chu and H. W. Spiess, J. Polym. Sci., Part B: Polym. Phys., 2009, 47, 138-155.

62 B. Langer, I. Schnell, H. W. Spiess and A.-R. Grimmer, J. Magn. Reson., 1999, 138, 182-186.

63 A. Samoson, T. Tuherm and Z. Gan, Solid State Nucl. Magn. Reson., 2001, 20, 130-136.

64 V. E. Zorin, S. P. Brown and P. Hodgkinson, J. Chem. Phys., 2006, 125, 144508.

65 H.-R. Xu, Q.-C. Zhang, Y.-P. Ren, H.-X. Zhao, L.-S. Long, R.-B. Huang and L.-S. Zheng, CrystEngComm, 2011, 13, 6361-6364.

66 D. E. Braun, K. P. Nartowski, Y. Z. Khimyak, K. R. Morris, S. R. Byrn and U. J. Griesser, Mol. Pharmaceutics, 2016, 13, 1012-1029.

67 O. F. Mohammed, D. Pines, J. Dreyer, E. Pines and E. T. J. Nibbering, Science, 2005, 310, 83-86.
68 B. H. Meier, F. Graf and R. R. Ernst, J. Chem. Phys., 1982, 76, 767-774.

69 L. Pauling and L. O. Brockway, Proc. Natl. Acad. Sci. U. S. A., 1934, 20, 336-340.

70 L. Leiserowitz, Acta Crystallogr., Sect. B: Struct. Sci., 1976, 32, 775-802.

71 I. Schnell, S. P. Brown, H. Y. Low, H. Ishida and H. W. Spiess, J. Am. Chem. Soc., 1998, 120, 11784-11795.

72 A. Böckmann, C. Gardiennet, R. Verel, A. Hunkeler, A. Loquet, G. Pintacuda, L. Emsley, B. H. Meier and A. Lesage, J. Biomol. NMR, 2009, 45, 319-327.

73 E. Davies, K. H. Müller, W. C. Wong, C. J. Pickard, D. G. Reid, J. N. Skepper and M. J. Duer, Proc. Natl. Acad. Sci. U. S. A., 2014, 111, E1354-E1363.

74 M. Xu and K. D. M. Harris, J. Am. Chem. Soc., 2005, 127, 10832-10833.

75 A. Krajnc, T. Kos, N. Zabukovec Logar and G. Mali, Angew. Chem., Int. Ed., 2015, 54, 10535-10538.

76 A. Tkatchenko and M. Scheffler, Phys. Rev. Lett., 2009, 102, 073005.

77 J. M. Griffin, A. J. Berry, D. J. Frost, S. Wimperis and S. E. Ashbrook, Chem. Sci., 2013, 4, 1523-1538.

78 J. Leclaire, G. Poisson, F. Ziarelli, G. Pepe, F. Fotiadu, F. M. Paruzzo, A. J. Rossini, J.-N. Dumez, B. Elena-Herrmann and L. Emsley, Chem. Sci., 2016, 7, 4379-4390.

79 Y. Ishii and R. Tycko, J. Magn. Reson., 2000, 142, 199-204.

80 E. K. Paulson, C. R. Morcombe, V. Gaponenko, B. Dancheck, R. A. Byrd and K. W. Zilm, J. Am. Chem. Soc., 2003, 125, 15831-15836.

81 B. Reif and R. G. Griffin, J. Magn. Reson., 2003, 160, 78-83.

82 Y. Nishiyama, Solid State Nucl. Magn. Reson., 2016, 78, 24-36.

83 B. M. Fung, A. K. Khitrin and K. Ermolaev, J. Magn. Reson., 2000, 142, 97-101.

84 B. Elena, A. Lesage, S. Steuernagel, A. Böckmann and L. Emsley, J. Am. Chem. Soc., 2005, 127, 17296-17302.

85 D. Sakellariou, A. Lesage, P. Hodgkinson and L. Emsley, Chem. Phys. Lett., 2000, 319, 253-260.

86 B. Elena, G. de Paëpe and L. Emsley, Chem. Phys. Lett., 2004, 398, 532-538.

87 J. P. Perdew, K. Burke and M. Ernzerhof, Phys. Rev. Lett., 1996, 77, 3865-3868.

88 D. Vanderbilt, Phys. Rev. B: Condens. Matter Mater. Phys., 1990, 41, 7892-7895.

89 S. Sturniolo, T. F. Green, R. M. Hanson, M. Zilka, K. Refson, P. Hodgkinson, S. P. Brown and J. R. Yates, Solid State Nucl. Magn. Reson., 2016, 78, 64-70. 